\title{
RANCANG BANGUN SISTEM PENGHITUNG JUMLAH PENGUNJUNG PERPUSTAKAAN MENGGUNAKAN METODE HAAR LIKE FEATURES (STUDI KASUS PADA PERPUSTAKAAN UNIVERSITAS TADULAKO)
}

\section{Designing System Counter Number of Visitors Library Using Haar Like Feature Method (Case Study At Tadulako University Library)}

\author{
Deny Wiria Nugraha ${ }^{1}$, Yusuf Anshori ${ }^{2}$, Ni Kadek Candriasih ${ }^{3}$ \\ 1,2,3 Jurusan Teknologi Informasi, Fakultas Teknik Universitas Tadulako; \\ e-mail: ${ }^{1}$ deny.wiria.nugraha@gmail.com, ${ }^{2}$ iyus.jr@gmail.com, ${ }^{3}$ Candriinformatika@gmail.com
}

Received 10 / 03 / 2018, Revised 15 / 04 / 2018, Accepted 18 / 04 / 2018

\begin{abstract}
Calculating the number of visitor, in a place or room is not easy. In line, it also occurs when we want to count the number of visitors in library. To know whether the number of visitor in library increases or not, the researcher formulated system that was used to count the visitor. It was Haar Like Features method. This method was used to count the number of visitor in library in a day.

In this study, Haar Like Features method was implemented to detect human as object. Beacuse of that, it had function as human object ditector and visotor ditector. By using this method, the librarians felt easier when they counted the visitor in a day. They also could calculate whether the number of visitor in library increased or not.
\end{abstract}

Keywords-Haar Like Features, images, system and Detection;

\section{Pendahuluan}

Menghitung jumlah pengunjung dalam suatu tempat bukanlah hal yang mudah dilakukan oleh manusia, khususnya dalam perpustakaan yang jumlah pengunjungnya sangat banyak. Untuk mengetahui apakah jumlah pengunjung perpustakaan setiap harinya meningkat atau menurun, maka dibuatlah sistem penghitung jumlah pengunjung agar dapat mengetahui berapa jumlah pengunjung perpustakaan setiap harinya, dan bila perhitungan ini dilakukan secara manual pastilah sangat menyulitkan pegawai dan kemungkinan akan masih terdapat kesalahan dalam perhitungan yang dilakukan oleh pegawai.

Pada penelitian ini penulis akan mengembangkan sistem yang sudah ada sebelumnya menjadi lebih spesifik lagi yaitu Sistem Penghitung Jumlah Pengunjung Perpustakaan Menggunakan Metode Haar Like Features.

Pendeteksian objek manusia maupun menghitung jumlah pengunjung dalam suatu tempat merupakan salah satu domain dalam aplikasi Computer Vision. Sehingga penulis ingin mengembangkan lagi mengenai pendektesian objek manusia ini dengan maksud agar sistem ini dapat digunakan dalam kebutuhan manusia. 


\subsection{Komputer Vision dan Citra}

Computer Vision berhubungan dengan perolehan gambar, pemrosesan, klasifikasi, pengenalan, dan menjadi penggabungan, pengurutan pembuatan keputusan menuju pengenalan [1].

Computer Vision adalah ilmu dan teknologi mesin yang melihat, di mana mesin mampu mengekstrak informasi dari gambar yang diperlukan untuk menyelesaikan tugas tertentu. Computer Vision adalah kombinasi antara Pengolahan Citra dan Pengenalan Pola. Pengolahan Citra (Image Processing) merupakan bidang yang berhubungan dengan proses transformasi citra/gambar (image). Proses ini bertujuan untuk mendapatkan kualitas citra yang lebih baik. Sedangkan Pengenalan Pola (Pattern Recognition), bidang ini berhubungan dengan proses identifikasi objek pada citra atau interpretasi citra. Proses ini bertujuan untuk mengekstrak informasi/pesan yang disampaikan oleh gambar/citra.

\subsection{Citra RGB}

$R G B$ adalah suatu model warna yang terdiri dari merah, hijau, dan biru, digabungkan dalam membentuk suatu susunan warna yang luas. Setiap warna dasar, misalnya merah, dapat diberi rentang nilai. Untuk monitor komputer, nilai rentangnya paling kecil $=0$ dan paling besar $=255$. Pilihan skala 256 ini didasarkan pada cara mengungkap 8 digit bilangan biner yang digunakan oleh mesin komputer. Dengan cara ini, akan diperoleh warna campuran sebanyak 256 × 256 x $256=$ 16.777.216 jenis warna. Bentuk representasi dari citra $R G B$ dapat dilihat pada gambar 2.1 berikut:

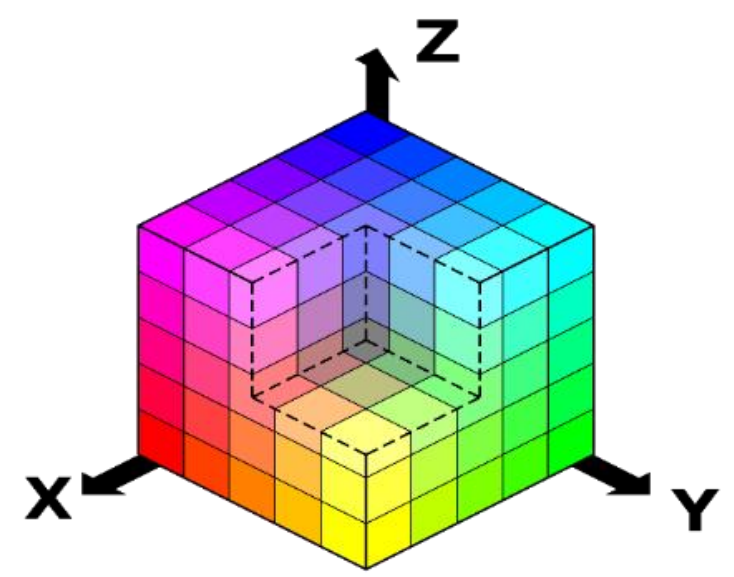

Gambar 1. Representasi citra $R G B[2]$

\subsection{Citra Grayscale}

Pada citra grayscale warna bervariasi antara hitam dan putih, tetapi variasi warna diantaranya sangat banyak. Citra grayscale disimpan dalam format 8 bit untuk setiap sample pixel, yang memungkinkan sebanyak 256 intensitas. Bentuk representasi dari citra grayscale dapat dilihat pada gambar 2 berikut: 


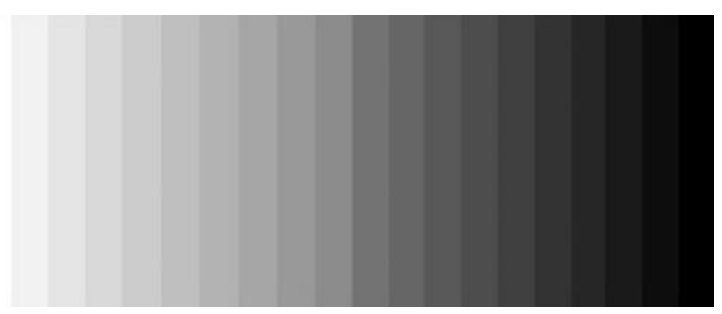

Gambar 2. Representasi citra grayscale [3]

\subsection{Sistem}

Sistem merupakan sekelompok unsur yang erat berhubungan satu dengan lainnya, yang berfungsi bersama-sama untuk mencapai tujuan tertentu [4].

Kata "sistem" banyak sekali digunakan dalam percakapan sehari-hari, dalam forum diskusi maupun dokumen ilmiah. Kata ini digunakan untuk banyak hal, dan pada banyak bidang pula, sehingga maknanya menjadi beragam. Secara umum, sebuah sistem adalah sekumpulan benda yang memiliki hubungan di antara mereka.

\subsection{Algoritma Haar Like Features}

Metode haar like features merupakan metode pendeteksian yang membutuhkan dua data set yaitu data positif dan data negatif, dimana data positif merupakan data yang berisikan objek yang akan dideteksi, dan data negatif merupakan data yang berisikan objek selain objek yang akan dideteksi. secara umum, Haar-Like Features digunakan dalam mendeteksi objek pada image digital.

Prinsip Haar-like features adalah mengenali obyek berdasarkan nilai sederhana dari fitur tetapi bukan merupakan nilai piksel dari gambar obyek tersebut. Metode ini memiliki kelebihan yaitu komputasinya sangat cepat, karena hanya bergantung pada jumlah piksel dalam persegi bukan setiap nilai piksel dari sebuah gambar [5]. Berikut merupakan bentuk representasi dari Berbagai variasi persegi Haar dengan Bobot Standar Persegi dapat dilihat pada gambar 3 berikut:
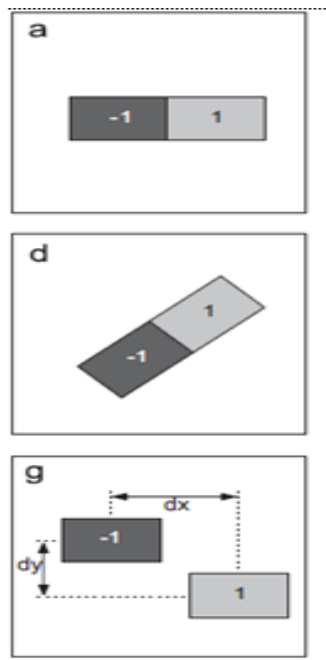
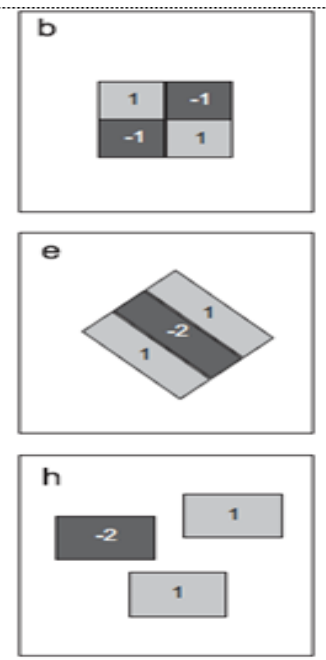
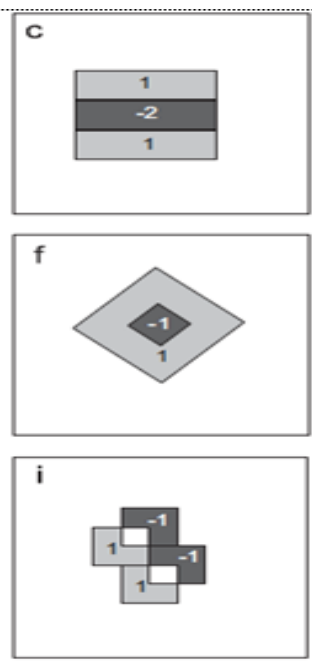

Gambar 3. Berbagai variasi persegi Haar dengan Bobot Standar Persegi Panjang [6]. 
Tahapan pemrosesan metode Haar Like Features yaitu sebagai berikut:

1. Tahap pertama yang dilakukan pada metode Haar Like Features ini adalah penangkapan citra atau gambar.

2. Tahap kedua yang dilakukan adalah pengubahan ukuran pixel atau tahap scaling.

3. Tahap ketiga yaitu mengubah gambar RGB kebentuk grayscale.

4. Tahap empat yang dilakukan adalah proses integral image matriks citra ditentukan menggunakan rumus berikut:

$$
\mathrm{s}(\mathrm{x}, \mathrm{y})=\mathrm{i}(\mathrm{x}, \mathrm{y})+\mathrm{s}(\mathrm{x}-1, \mathrm{y})+\mathrm{s}(\mathrm{x}, \mathrm{y}-1)-\mathrm{s}(\mathrm{x}-1, \mathrm{y}-1)
$$

Keterangan:

$\mathrm{s}(\mathrm{x}, \mathrm{y})$ : komulatif jumlah kolom

$\mathrm{i}(\mathrm{x}, \mathrm{y})$ : nilai piksel dari image pada posisi $\mathrm{x}, \mathrm{y}$

Tahap kelima mencari nilai fitur Haar dari area matriks dengan menggunakan rumus berikut:

$$
\mathrm{i}\left(\mathrm{x}^{\prime}, \mathrm{y}^{\prime}\right)=\mathrm{s}(\mathrm{A})+\mathrm{s}(\mathrm{D})+\mathrm{s}(\mathrm{B}) \mathrm{s}(\mathrm{C})
$$

Keterangan:

A: adalah nilai-nilai matriks integral yang sudah diperoleh dan akan digunakan untuk menghitung nilai fitur Haar

\section{Metode Penelitian}

\subsection{Bahan Penelitian}

Dalam penelitian ini, bahan penelitian yang akan digunakan adalah:

1. Studi Literatur

2. Manusia (Pengunjung Perpustakaan)

\subsection{Alat Penelitian}

Untuk mendukung sistem penghitung jumlah pengunjung perpustakaan dengan menggunakan metode haar like feature ini, digunakan perangkat keras dengan spesifikasi processor Core i3 2,50 GHz, RAM 2 GB, Monitor dengan resolusi 1366x768, dan web camera sebagai media penangkap citra.

Untuk implementasi perangkat lunak digunakan bahasa pemrograman Visual Basic 2012 sebagai media pembuatan dan perancangan sistem, Emgu $C V$ yang merupakan library khusus untuk pengolahan citra, MySQL Connector.Net dan MySQL Connector sebagai media penghubung antara bahasa pemrograman dengan database server. 


\subsection{Tipe Penelitian}

Tipe penelitian yang digunakan adalah tipe penelitian kualitatif berbasis eksperimen. Penelitian eksperimen adalah penelitian yang berusaha mencari pengaruh variabel tertentu terhadap variabel lain dengan kontrol yang ketat [7].

\subsection{Lokasi Penelitian}

Penelitian ini dilakukan di Perpustakaan Universitas Tadulako, Palu Sulawesi Tengah.

\section{Hasil dan Pembahasan}

Pada sistem penghitungan jumlah pengunjung perpustakaan terdapat beberapa form yang telah dibuat dan berfungsi sebagai media masukan:

1. Menu tama

Menu utama ini digunakan untuk menampilkan tampilan utama pada saat program dijalankan, berikut gambar 4 yang merupakan tampilan utama dari program:

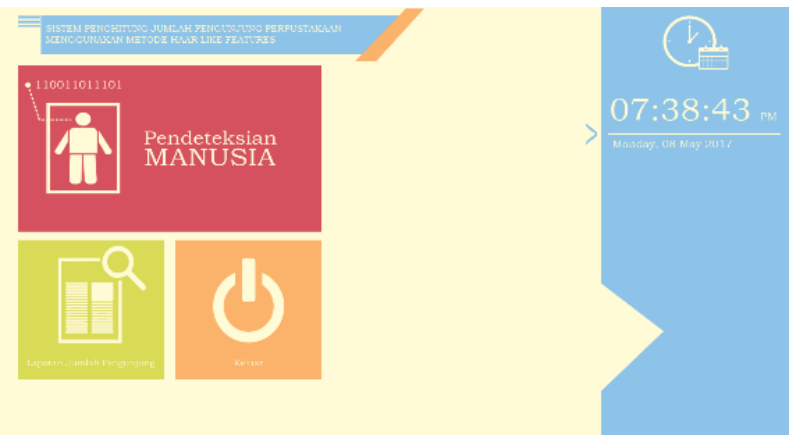

Gambar 4. Form Tampilan Utama

2. Mendeteksi objek

Fungsi ini digunakan untuk mengetahui jumlah pengunjung yang datang keperpustakaan dengan cara mendeteksi objek. Objek yang di maksud adalah manusia. Berikut gambar 5 tampilan utama dalam pendeteksian manusia
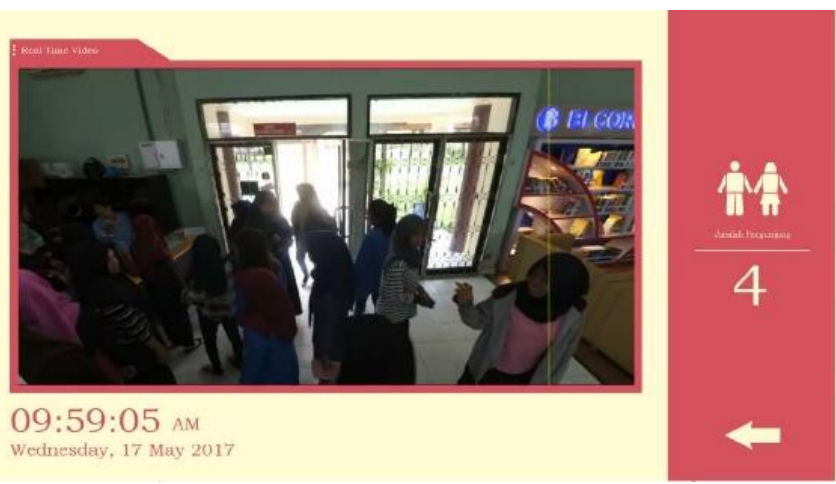

Gambar 5. Form Pendeteksian 


\section{Form Laporan}

Form Data Laporan, Form ini berupa tampilan aplikasi sistem penghitung jumlah pengunjung yang fungsinya untuk melihat data yang telah tersimpan dalam database, pencariannya dapat dilakukan dengan menekan tombol pencarian, dalam form ini juga dapat mencetak hasil jumlah pengunjung guna untuk membuat laporan jumlah pengunjung. Berikut gambar 6 tampilan form data laporan:.

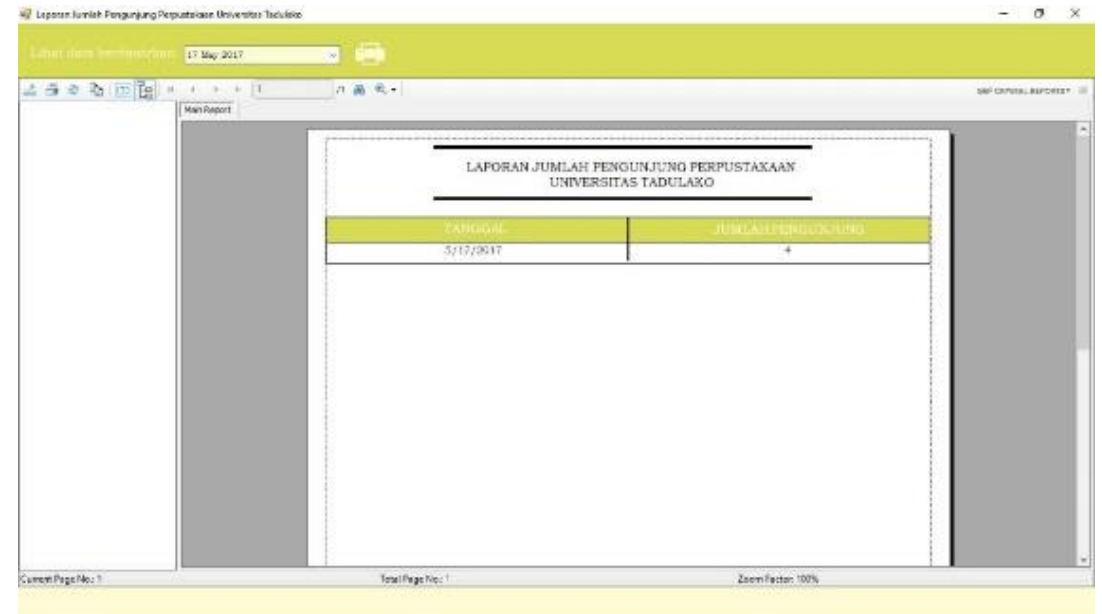

Gambar 6. Form Laporan

\section{Kesimpulan}

Berdasarkan pengujian dan analisis sistem penghitung jumlah pengunjung perpustakaan menggunakan metode haar like features, maka dapat diambil kesimpulan sebagai berikut:

1. Metode haar like features merupakan metode pendeteksian yang membutuhkan dua data set yaitu data positif dan data negatif, dimana data positif merupakan data yang berisikan objek yang akan dideteksi, dan data negatif merupakan data yang berisikan objek selain objek yang akan dideteksi. Kemudian metode tersebut akan membuang data latih negatif, sehingga didapat suatu keputusan untuk menentukan data positif.

2. Metode haar like features dapat diimplementasikan dalam pembuatan aplikasi sistem penghitung jumlah pengunjung perpustakaan menggunakan metode Haar Like Features.

\section{Saran}

Diharapkan pada penelitian sistem penghitung jumlah pengunjung perpustakaan menggunakan metode Haar Like Features ini dapat dimanfaatkan sesuai dengan yang diharapkan dan apabila ada yang berminat untuk menganbil penelitian yang hampir sama dengan penelitian diatas bisa menambahkan lagi fungsi-fungsi atau suatu algoritma khususnya untuk mendeteksi objek manusia agar lebih akurat untuk mendeteksi.

\section{DAFTAR REFERENSI}

[1] Adrian Low. 1991. Introductory Computer Vision and Image Processing, Mc Graw Hill.

[2] Diah Ayu Lukita, Citra RGB,http://digilib.ittelkom.ac.id, diakses: 10 April 2013. 
[3] Johnson, Citra grayscale, https://scholar.google.com/scholar?q=citra+grayscale+johnson+1998\&hl=id\&as sdt=0\&as _vis=1\&oi=scholart\&sa=X\&ved=0ahUKEwidmeHL86fUAhVFsY8KHWf1APcQgQMII DAA, diakses 10 april 1998.

[4] Mulyani. 2001. Pengertian sistem, Salemba. Jakarta.

[5] Paul, V., Jones, M. 2001. Rapidobject detection using boosted cascade of simple features. In: Proceedings IEEE Conf. on Computer Vision and Pattern Recognition.

[6] Pavani S.K., Delgado D., Frangi A.F., 2010. Haar-like features with optimally weighted rectangles for rapid object detection. Center for Computational Imaging and Simulation Technologies In Biomedicine (CISTIB).

[7] Sedarmayanti \& Syarifudin Hidayat. 2002. Metodologi Penelitian, Mandar Maju, Bandung 